\title{
Regenerating the "Creative Place": A New Approach in Promoting Contemporary Heritage of Islamic -Iranian City (Case Study: Naqsh-E-Jahan Square of Isfahan)
}

\author{
MINOU GHAREHBAGLOU ${ }^{1 *}$, AHAD NEJAD EBRAHIMI ${ }^{1}$ and ELAHE AGHAJNI ${ }^{2}$ \\ ${ }^{1}$ Assistant Professor in Faculty of Architecture \& Urbanism, Tabriz Islamic Art University, Tabriz, Iran. \\ ${ }^{2}$ M.Sc Student in Architecture, Architecture \& Urbanism Faculty, Tabriz Islamic Art University, Tabriz, Iran. \\ http://dx.doi.org/10.12944/CWE.9.3.57
}

(Received: November 17, 2014; Accepted: Decemeber 11, 2014)

\begin{abstract}
Regenerating the historic cities and adapting them with the circumstances and developments of contemporary life is one of the essential strategies for improving the social, economic and cultural situations in historic cities. The changes of socio-cultural conditions have necessitated more attention to high potential urban contexts such as historic hubs for improving the mentioned conditions. This research aims at studying a recent phenomenon in cities based on social, cultural and economic innovations called "creative place". The objective of the theory of "creative place" is developing strategies for achieving a new model of sustainable development that is consistent with the spirit of time in response to the following question: "How can we achieve the concept of creative place as a new model of sustainable development based on culture and identity in regenerating the historical centers of a modern Islamic-Iranian city?" .According to the approach of "sense of place" and using interaction between the three areas discussed in the creative place, i.e., Art \& Culture, Knowledge-based organizations, and Community projects, this subject is analyzed using content analysis method and reviewing the literatures. Then the environmental components in renewing the historical hubs of Iranian-Islamic contemporary city is detected using the approach of "creative place" .In the final step, the environmental factors of Naqsh-e-Jahan Square of Isfahan are recognized and analyzed in order to become a creative place. This study concludes that recognizing the features of contemporary heritage of architecture and Islamic urbanism of Iran in order to establish a basis for the realization of creative place idea, leads to the recognition of the rich factors involved in this heritage.
\end{abstract}

Key words: Creative Place, Regenerating, Historic Hub, Iranian-Islamic city, Isfahan.

\section{INTRODUCTION}

From the 1970s, changes in programs, urban policies and practices implemented a new concept of policies and practices within the cities. In this period, more scholars, writers and urban planners spoke about the reinvention and originality of the historical contexts. (Madani Pur, 2007). Based on a systematic view, by focusing on the historic cores of the cities enjoying the maximum capacity and background in urban life, cities and urban areas can be transformed into a competitive dynamic set. Management and planning on regenerating historic sites and the primary cores of the cities as multifunctional spaces, have the ability to attract diverse groups of citizens and the emergence of social activities in these environments will lead to increased community interactions, space interactions and materialization of the public activities. This is an approach which is followed in post-industrial terms of the cities of the developed countries with the approach of cultural landscape restoration 
(Farahmand, 2010) .Following this concept has always been associated with the concept of creative place that has been interpreted with various definitions. The model of creative regeneration is seeking for places that can attract the creative classes and groups (of people), and maintain them so that urban areas to become the main arena for competition in the highly revolutionized global conditions (Florida , 2010) .The first point to the creative city as a sense took place in Melbourne by Charles Landry at a seminar organized by the Ministry of Planning and Environment of Australia in 1988 . He was not only the originator of the concept of "creative", but also advisor of Great Britain planning projects and implementer of many cultural projects and studies as well. Then, Richard Florida founded the "Creative Class" concept. World experiences in relation to the establishing of creative cities in Toronto and Canada are running in the field of research and studies phase. Also, Melbourne, Adelaide and London can also be considered among the first "creative cities". These cities according to a strong social and cultural infrastructure and through their advantageous facilities are the centers of creativity and investment and have placed more attention on historic centers of the cities, and benefiting from a city approach and creative place have attempted to revitalize the historic hubs of cities.

\section{Questions and Methodology}

This paper, for responding the question saying that "what are the identifiable environmental components in the contemporary heritage of Iranian - Islamic city for establishing a creative place?" attempts to analyze the existing infrastructures in the spatial - fundamental structure of contemporary Iranian - Islamic city to reproduce and emphasize on these components in line with the formation of the creative places. The Research Methodology of this paper is content analysis which is performed in three steps. The first step, using a theoretical approach, identifies the factors influencing the establishment of creative place. In the second step, it attempts to develop the influential parameters in the historic centers of the contemporary Iranian-Islamic city for designing a creative place with regard to standards based on the city's culture and identity. Finally, in the third step, using the data obtained during the previous two stages, these components in Naqsh-
e-Jahan Square of Isfahan, as the contemporary heritage of Isfahan will be recognized.

\section{Creative City, a new approach in urban renewal}

Renewal means the production of new space organization, in accordance with the terms of the new features, all of which are effective in establishing new urban relationships or redefining existing or old urban relationships .In this approach, considering the preservation of cultural values as well as indigenous and historical treasures, the criticism of the constructions with identical application instead of multiple applications, paying attention to qualitative measures along with quantitative measures and the participation of different social groups in regenerating process is evident (Pur Ahmad, 2009 ).

Charles Landry as the founder of the idea of creative city believes that historical perspective will always be carrier of creativity and live stream to the cities and since the cultural arena is the most important challenge of future life, victory or defeat in this field determines the future of the city as well (Hall, 1999) . According to Landry (2008) creative communities are very active and benefit from human places nurturing personal growth in cultural and technological developments generating jobs and wealth accepting the diversity of lifestyles and culture (cctf, 2008) .The concept of creative city , already constitutes a basic idea that requires extensive studies. Creative city offers essential features to foster creativity of the resident people. The concept of creative city and creative place are as a fluidized, networked, and open community that accept diverse category of age and population with fresh ideas, capital diversity and are risk-taking as well (Landry, 1995). Creative city is a place for the development of creativity and this potential is intensified by the creative place which is an attractive place for works and lives of citizens (especially youngster) and is an attractive place for tourists (tourism industry) and is a capable place for flourishing different economic sectors (especially through the use of art economy), and the development of new research centers (especially in new technologies) (Ebrahami, 2007).

For having a creative city, the existence of creative infrastructure is essential which consists of 
a combination of software infrastructures, including a flexible and skilled workforce and dynamic thinkers as the implementers of intellectual space of the city and hardware infrastructure includes buildings, locations and communication networks. Due to various areas to create urban creativity, in this paper, only the hardware infrastructure and the role of place in shaping and creating a place for absorption and development of new concepts such as creative city are investigated.

\section{The importance of regeneration of historic hubs in establishing a creative city}

In the cities that are signs of social identity, although the economy and society are strongly influenced by the form and function, but we can help to improve those places in the new changes of urban centers by regeneration of similar qualities of successful cities in the past with the typical sample of urban life. Seven basic principles in the efficient urban regeneration of the city are as follows:(Prumier, 2004)

\section{Promoting diversity of use \\ 2. Increasing motivation \\ 3. Increasing the course of development \\ 4. Confidence about a balance of activities \\ 5. Expanding access \\ 6-Establishing functional connections \\ 7-Establishing a positive identity}

Considering the locations with features such as alive and dynamic and spatial supplier with offering opportunities, facilities and services in order to increase the public's growing desire the for presence in space including the important historical cities. To redefine and expand the position of the cities, at local, regional and transnational level as well as managing the balance between extraversion and local nobility, the potential of the historic centers of the cities will be discussed to improve urban life conditions through innovative processes of development (Landry, 2008). Certain qualities in the historic centers of the cities such as access, diversity of use, focus and intensity of use, organization and structure cause that people tend to business, shopping and live in these places (Prumier, 2004).
Cities with thriving economies in the world actively pursue regeneration strategies of urban historical hubs to build successful and efficient cities for work, living, shopping and renewal. Literatures of regeneration of historic hubs of cities show that the character of selection and application of strategies regeneration, are dynamic and diverse along with time (Singhal, 2009). Considering that Florida's researches (2010) have indicated the key role of place quality in attracting and retaining creative team, the historic centers of the cities are of strategic importance. Because, the wide variety of urban activities in one place is considered as the crucial part of the city is considered as the heart and the driving force of each city, which has the greatest capacity to actualize the creative cities, through the creation of creative places (Landry et al., 1995).

\section{Creative place, a mechanism for establishing the creative city}

In the definition of "urban regenerating" with the approach of creative urban spaces, the concept of place plays a key role. What the creative urban areas are seeking for, are adaptable with physical, functional notions and image of place. Because in most cases, the entire of a city cannot be a creative city, but a part of a city can be a creative place, that today are said cultural centers or clusters of creative industries (Montgomery, 1998). Montgomery stated that majority of creative cities possess distinctive places where attract artists and lettered people. He proposed some necessary features for the success of these places as follows:

- The presence of variety of cultural facilities

- Vitality

- The existence of places where community

- Educational Facilities

- The amount and quality of public places

- providing an image of the identity of the of the place

- Readability

Montgomery knows one of the reasons for creative places in the kind of activities of that place that should be diverse as much as possible. In his opinion, without the presence of a basic economic activity, there is no possibility for the creation of creative places (Montgomery, 2003: 295). According 
to his view, creative place should also provide social and cultural activities aspects to lead to appear of creative sectors and areas as identifiable clusters in the view of the city. Therefore, the creative places are taking shape via economic activities grouping, institutions and cultural and scientific resources, and represent a social environment and open territory so that density, diversity, and aesthetic and coherence and increased production and creative activities can interact together (Landry ,2008). Areas and creative places are established in two ways: stimuli.

Spontaneous and resulting from unplanned

- Planned, as centers to consolidate, strengthen and commercialize.

Creative places are the result of three phenomena of Art \& Culture, Knowledge-based organizations and Community projects. (Florida, 2010) that alone do not lead to a creative community but their association generates a creative place (Figure 1).Their simultaneous composition and crosses along with the development create some places in the city that play role in the concept of establishing a creative place.

\section{Art and Culture}

Harvey Perloff et al (1979) argue that cultural compatibilities and the quality of life

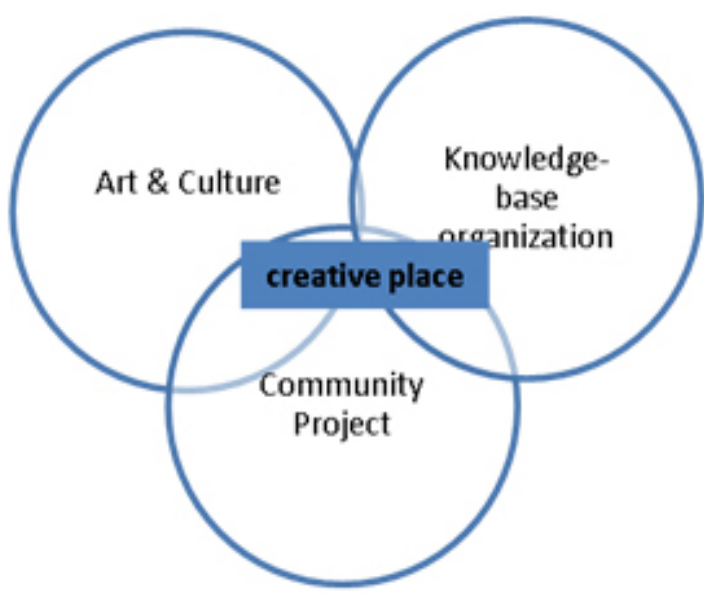

Fig. 1: Constituent elements of creative placeSource: authors in society are linked to economic development and job creation. This program created the economic impact studies of the arts in the world. On the other hand, urban planners point out that the effective cultural programming includes all the arts and the cultural resources in community and urban development (Dadpour, 2010).

\section{Knowledge-based organization}

schemes based on knowledge, are defined as fundamental preconditions for a successful move towards a knowledge-intensive economy, with the ability to change the system and creativity (Manzini, 2008). For a knowledgebased economy, a knowledge proactive society is needed. Knowledge-based companies should be well trained and provide dynamic man-power in the stimuli social fields to generate creative places which are a potential for exploiting the knowledgebased competition (Manzini, 2008).

\section{Community Projects}

Transition from the industrial age to the knowledge age, globalization and the problems facing it has brought variations and changes and new requirements in lifestyle (Giddens, 2001). Responding to challenges of everyday life according

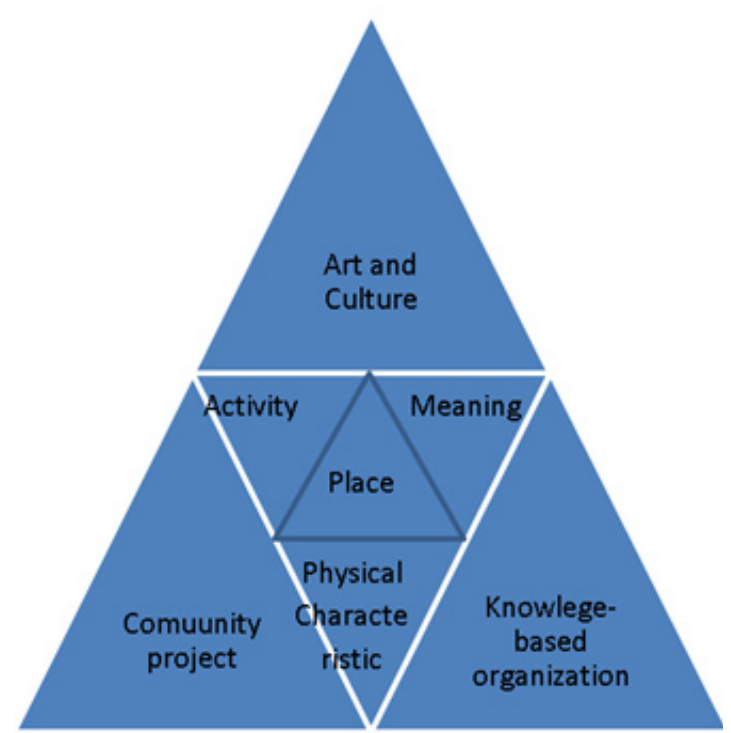

Fig. 2: A conceptual model of creative place in regenerating historic hubs of contemporary Iranian- Islamic city, Source: authors 
Table. 1: Creative spatial factors for regenerating historic hubs of contemporary Iranian-Islamic city. Source: the authors.

\begin{tabular}{|c|c|c|c|}
\hline $\begin{array}{l}\text { Oreative } \\
\text { Place } \\
\text { Place }\end{array}$ & Art and Culture & $\begin{array}{c}\text { Knowledge-based } \\
\text { Organizations }\end{array}$ & Community Projects \\
\hline$\frac{D}{\stackrel{D}{2}}$ & $\begin{array}{l}\text {-Cansidering some } \\
\text { places to implement art } \\
\text { in flexible spaces } \\
\text { - Avail bility of spaces } \\
\text { such as gardens, } \\
\text { squares, street corners } \\
\text { with possibility of } \\
\text { watching and doing } \\
\text { various activities such as } \\
\text { cultural perfom ances } \\
\text { (Montgomery, 1998). }\end{array}$ & $\begin{array}{l}\text { - Creation of databases } \\
\text { of city information } \\
\text { (Landy, 2008? } \\
\text { - Pram oting } \\
\text { technological and } \\
\text { virtual activities in the } \\
\text { place (Landry, 2008) } \\
\text { Providing public } \\
\text { education in the place. }\end{array}$ & $\begin{array}{l}\text { - A variety of public spaces in renewal and } \\
\text { - Thopping. } \\
\text { ceremories and festivals. } \\
\text { - The existence of places for nightlife } \\
\text { activities and music activities (S am adi, } \\
\text { 2012) } \\
\text { - Avail ability of functional areas such as } \\
\text { cinemas, theaters, restaurants and public } \\
\text { meeting places (Montgornery, 1998) } \\
\text { - The fresence of active street life and } \\
\text { public are as. (Montgomery, 1998) } \\
\text { - Availability of spaces such as gardens, } \\
\text { squares, street corners With the ability to } \\
\text { watch and do various activities such as } \\
\text { cultural performances (Montgomery, } \\
\text { 1998) }\end{array}$ \\
\hline 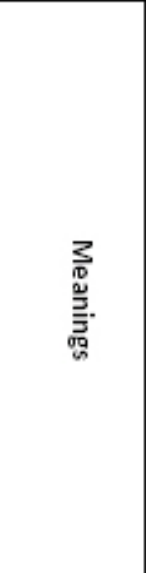 & $\begin{array}{l}\text { - Upgrading the identity } \\
\text { by promoting } \\
\text { traditiona arts to } \\
\text { strengthen the } \\
\text { authenticity of the arts. } \\
\text { - Maintaining and } \\
\text { strengthening the } \\
\text { strategic landscapes of } \\
\text { the city consisting of } \\
\text { o pening corrido rs of } \\
\text { visibility to the signs of } \\
\text { city (Landry, 2008) }\end{array}$ & $\begin{array}{l}\text {-Displaying the } \\
\text { method of } \\
\text { maintenance and } \\
\text { restor ation of historic } \\
\text { spaces - in order to } \\
\text { promote identity and } \\
\text { increasing the public } \\
\text { knowledge. (Landry, } \\
\text { 2008) } \\
\text { - The use of urban } \\
\text { signsfor city branding, } \\
\text { creation and } \\
\text { strengthening } \\
\text { of identity (Landry, } \\
\text { 2008) }\end{array}$ & $\begin{array}{l}\text { - Multicultural view of city } \\
\text { - Creating commu nity together through } \\
\text { social ization, oriented and } \\
\text { participatory places (Landry, 2008) }\end{array}$ \\
\hline 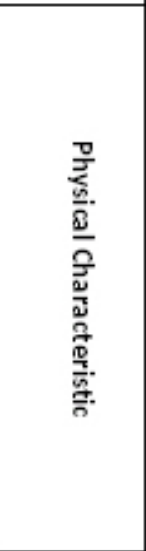 & $\begin{array}{l}\text { - Availability of some } \\
\text { spaces various gardens, } \\
\text { squares, street corners } \\
\text { that create the } \\
\text { posibility f watch and } \\
\text { daing various activities } \\
\text { such as cultual } \\
\text { performances } \\
\text { (Montgomery, 1998) } \\
\text { - Having a degree of } \\
\text { creativity in } \\
\text { architecture, with a } \\
\text { variety of styles, genres, } \\
\text { and architectural design } \\
\text { (Montgomery, 1998) }\end{array}$ & $\begin{array}{l}\text { - Observing the } \\
\text { advancesin } \\
\text { technology and } \\
\text { manufacturing } \\
\text { - Displaying the } \\
\text { method of } \\
\text { maintenance and } \\
\text { restor ation of } \\
\text { historical-cultural sites } \\
\text { in order to promote } \\
\text { identity and increasing } \\
\text { the public knowledge. } \\
\text { (Landry, } 2008\end{array}$ & $\begin{array}{l}\text { - Providing places for open, inclusive and } \\
\text { - participatory ativities. } \\
\text { - Providing variety and quality of public } \\
\text { - Maintaining and enhancing the natural } \\
\text { environments and green spaces. } \\
\text { - Ensuring the quality of movement and } \\
\text { access. } \\
\text { - providing a variety of shipping options. } \\
\text { - Using combined applications as much as } \\
\text { - possible. (Montgomery, 1998) } \\
\text { streetmarkets(Montgomery, 1998). }\end{array}$ \\
\hline
\end{tabular}


to social prospects in which the promotion of initiatives by citizens, focus on specific areas and motivating people through creating socialization places that anyone actively and directly is involved in achieving the outcome of his/her work is paid attention highly (Manzini, 2008).

Table. 2: Recognition of environmental factors in Naqsh-e-Jahan Square of Isfahan Source: the authors

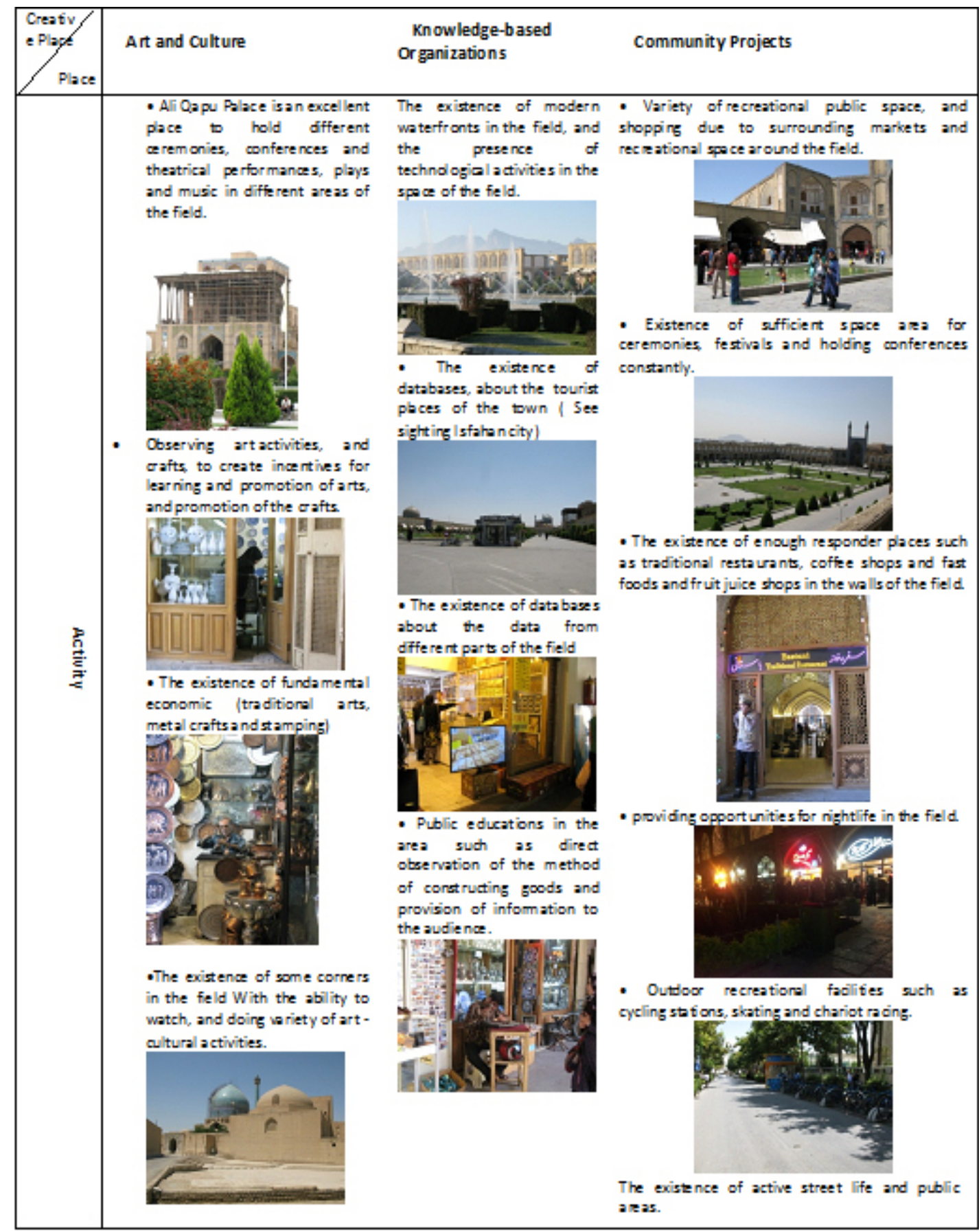


Regeneration of creative place in the historic centers of Iranian - Islamic contemporary city

Canter (1977), defines a place consisting of three elements of activity, the physical characteristics and meanings. Canter (1977), Montgomery
(1998) attempted to study successful places and identification of factors to release the notion of place from an abstract concept and generalize it to the concepts of place and sense of place.

Table. 2: (continue) - Recognition of environmental factors in Naqsh-e-Jahan Square of Isfahan Source: the authors

\begin{tabular}{|c|c|c|c|}
\hline $\begin{array}{l}\text { Creativ } \\
\text { e Plage }\end{array}$ & Art and Culture & $\begin{array}{l}\text { Knowled ge-based } \\
\text { Organizations }\end{array}$ & Comm unity Projects \\
\hline 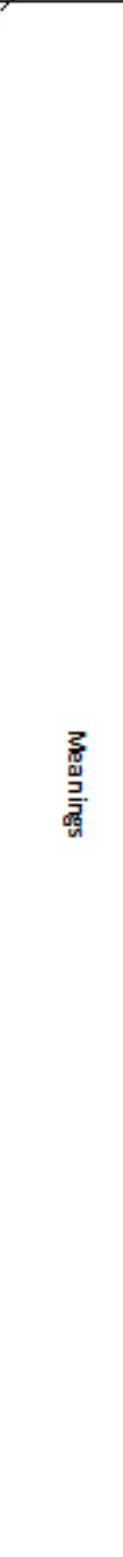 & $\begin{array}{l}\text { - strengthening the identity and } \\
\text { authenticity of the city, while } \\
\text { locating in the space of the field } \\
\text {, through the observation of } \\
\text { islamic rich architecture } \\
\text { - Playing music and images of } \\
\text { city in the markets around the } \\
\text { square } \\
\text { - Observing crafts and creation } \\
\text { of incertives to promote } \\
\text { traditional arts and promotion } \\
\text { of handicraft value } \\
\text { fei if }\end{array}$ & 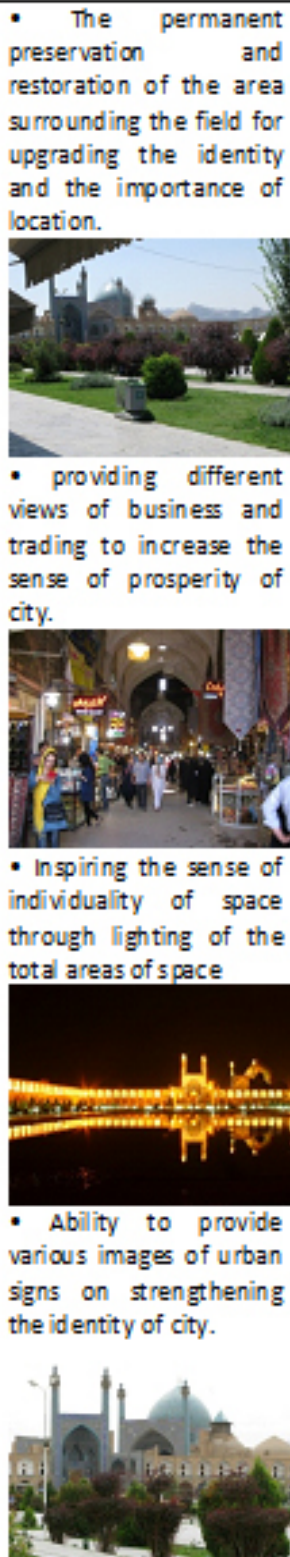 & $\begin{array}{l}\text { Display of multiculturalism of city } \\
\text { through the availability of shops } \\
\text { and restaurarts of different ethnics. } \\
\text { - The possibility of social integration } \\
\text { because of existence of public places, } \\
\text { integrated and collaborativeplaces. }\end{array}$ \\
\hline
\end{tabular}


What known in the Iranian - Islamic architecture as the historic site are the experiences of people who were conveyed from generation to generation and included significant elements of space, decoration, geometry, etc. Historic sites are places in which meaningful elements exist, constructing them is difficult because new memories and myths are made gradually and over the history,

Table. 2: (continue) - Recognition of environmental factors in Naqsh-e-Jahan Square of Isfahan Source: the authors

\begin{tabular}{|c|c|c|c|}
\hline $\begin{array}{l}\text { Creativ } \\
\text { e Place }\end{array}$ & Art and Culture & $\begin{array}{l}\text { Knowledge-based } \\
\text { Or ganizations }\end{array}$ & Community Projects \\
\hline 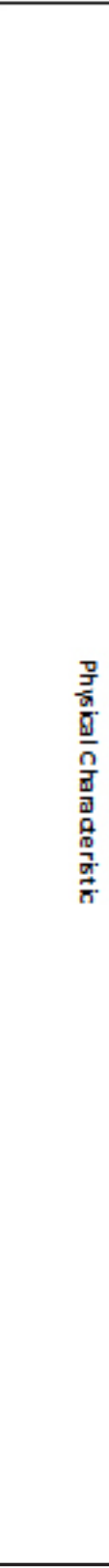 & $\begin{array}{l}\text {-Enjoying high level of } \\
\text { architectural quality, through } \\
\text { connecting to the valuable } \\
\text { historical elements of the city } \\
\text { such as chehelsotoon, His torical } \\
\text { banks, municipal building with } \\
\text { creating a fully functional } \\
\text { network and linked to specific } \\
\text { locations. } \\
\text { Po } \\
\text { - The availability of spaces to } \\
\text { allow viewing of various activities } \\
\text { such as Ali Qapu Palace for } \\
\text { holding the cerem onies. }\end{array}$ & $\begin{array}{l}\text { - The existence of some spaces } \\
\text { in markets around the square } \\
\text { for virtual education of } \\
\text { production of required goods. } \\
\text { - showing the preservation and } \\
\text { restoration of the enviromment } \\
\text { to promote the importance of } \\
\text { identity and place. }\end{array}$ & 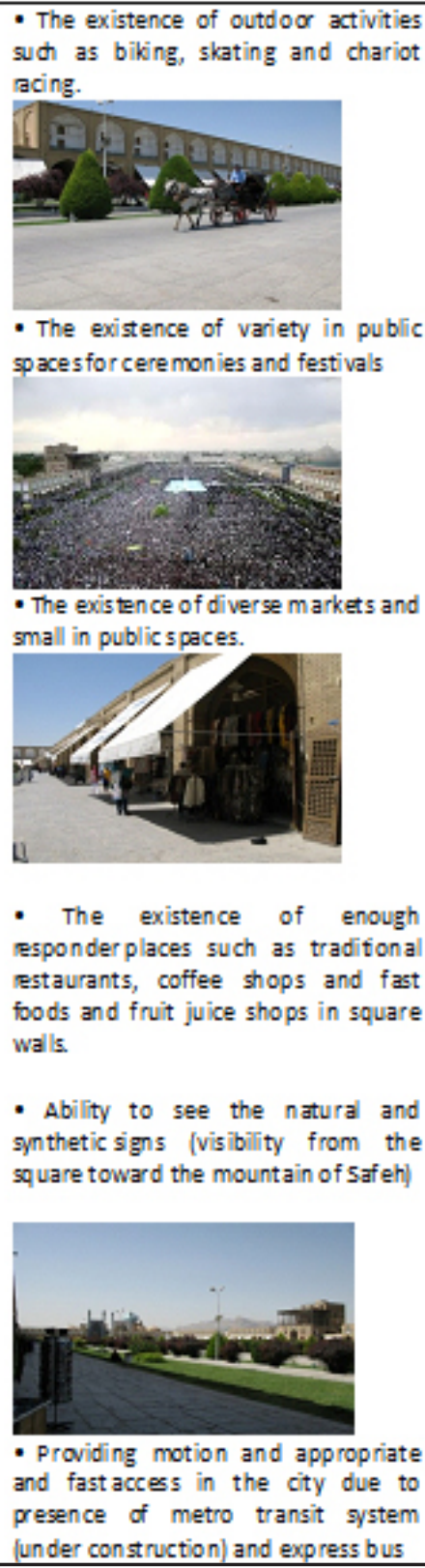 \\
\hline
\end{tabular}


(Rotenberg, 2012: 241). Historical places of Iran are the result of the interaction between natural and artificial elements to create an architectural space and it's clear example can be creating varieties such as Iranian gardens, markets, houses, mosques that in addition to considering the function element and activity identifies and applies concepts and meaningfully. Water and light in appearance are considered as fully functional elements and are raised for the use of physical needs, but they always have kept their symbolic role and meaning as well. In historic sites of Iran's architecture and urbanism, it has been attempted to cause human's attachment to the environment in seemingly simple designs, but with semantic complexity. This means that, these places may seem simple at first glance but this simplicity is more due to the purity of the used shapes in the design and arrangement of the compounds and if we pay attention accurately, the subtleties appear in terms of internal composition and the relationship with the various sections of the closed environment (Navaii, 2010, 318). Activity and meaning are the two elements that regardless of architectural body cannot keep their entity. Body in Iranian - Islamic approach has an approach adapted to the culture and technical ability of various geographical regions and thus this has caused the variety of architectural structures of Iran.

The variety of structures in Iranian- Islamic architecture and urbanism is not only consisting of diversity of architectural structures of Iran but this design includes the tiniest thing in decoration of role and the selection of colors in wall decorations of architectural forms to urban spaces and public squares. And each of these can be analyzed in terms of location and impact on the formation of sense of place. Based on the literatures studied and using three defining components of place from the perspective of Canter and three phenomena consisting of creative place, Figure 2 presents a conceptual model of creative place to regenerate the historical hubs of Iranian - Islamic contemporary city.

Based on the conceptual model presented in Figure 2, and studies of creative place, and on the basis of sense of place, Table 1, provides olutions to establish a creative place in the historic hubs of contemporary Iranian - Islamic city
Investigating the potential of Isfahan city to become a creative city

Taking a look at Isfahan city, we can find places built according to urbanization principals, and creative hubs in this city. The main potential of Isfahan city to become a creative city is the historic hubs in this city that are vibrant and lively centers of the city. Isfahan city, because of enjoying many job opportunities, and meeting the needs of different age groups of citizens has absorbed a large number of immigrants from different cities .And therefore this has caused the presence of many religious and ethnic minorities in this city.

In order to develop a creative hub, we must first study the specific characteristics of regions such as the quality of cultural, demographic, and social sources, etc. (Kourtesis, 2008:256). Isfahan has historical, cultural, social, educational and religious centers that can be used to achieve the idea of creative place. Although all the standards of creative place and creative city are not consistent with cultural - social status quo of Isfahan, but among the commonalities, we can achieve the effective quality standards in the historic hubs of city of Isfahan, with an approach to establish a creative place. Naqsh-e-Jahan Square of Isfahan has the capability to become the creative hub of the city due to enjoying socio-political and cultural features as the potentials of a creative hub .In this regard, following the regeneration of the territory of Naqsh-e-Jahan Square of Isfahan we can try to change its visit-only face to one of the advertising cultural pubs of the world. Moreover, we can attempt to study strategies to recreate it by considering the necessary potentials for converting this place to a creative place. Table 2, tries to recognize capabilities of Naqsh-e-Jahan Square of Isfahan in order to become a creative place for regeneration of IranianIslamic city fitting the spirit of time and presenting ways to improve it.

\section{CONCLUSION}

Regeneration of cities, especially historical hubs is a concern for all cities in the world, especially in cities of developing countries including Iran. In this approach, although the renewal of old body of cities is considered, but somehow the adaptation of cities with today and the future needs is also an important 
goal of urban management. Paying attention to this matter to regenerate the historic city hubs, represent the resuscitation of these hubs in accordance with prominent and contemporary approaches such as city and creative place increasingly. With studying about the cities that despite having valuable historical hubs and necessary facilities to people's lives and a variety of racial and ethnic minorities, as well as a diverse mix of opportunities have the necessary potentials for a new approach of re-generation, a title like "creative city" can be applied.

Considering the fact that, today, the need for change is evident in the urban environments, by regenerating some spaces in the city with an approach to establishment of a creative place; we can approach the idea of realizing a creative city based on the sustainable development of arts and culture. To use the historical hubs capabilities to conform to the pattern of creative place, in addition to enjoy space capabilities, the promotion of social, cultural and economic areas should also be considered and for taking advantage of the unique capabilities of these places, some principles should be used in renewing them that is, each town is subject to its cultural and social issues terms and its process of formation is a function of climate, historical, cultural, religious, ecological and aesthetic conditions. Thus, the theoretical foundations of regeneration are the contemporary heritage and intervention in the context of urban cities and even different neighborhoods of cities should be diverse and specific to achieve the process of dissection and operation of contexts to somehow that transplanted organs not be socially rejected later.
By studying the existing theories to establish a creative place, the regeneration of historical hubs using a defensible set of policies in the concept of creative city which is definable in a certain area of within the cities and especially valuable historical contexts, considering the physical aspects and quality of space, flexible activity context, dynamicity and inclusivity of space. The existence of senses of meaning and understanding of space, the existence of some places for shaping careers, and social interactions context, promotion of technology in development and a set of economic, social and cultural factors can help to achieve these goals.

According to studies, Isfahan can be defined as a creative city in terms of having numerous historic hubs that have the capabilities of creative place. And also we can identify the capabilities of this field to become a creative place in three areas of activity, sense and body. Understanding each of these factors is generally highly essential in decision making and planning and specifically in the design and implementation as a new approach in introducing contemporary heritage of Iranian Islamic city and the selection of optimal application practices.

\section{ACKNOWLEDGEMENT}

This paper has been extracted from the Master of Science thesis of the third author which has been conducting under the supervision of first author and advisory of the second author submitted in the faculty of Architecture \& urbanism, Tabriz Islamic Art University, Tabriz, Iran.

\section{REFERENCES}

1. Madani Pur, Ali., Urban Environment Design, translated by Farhad. Mortezai, Tehran, Pardazesh Publications and urban planning (2007)

2. Nosum, Pan, The Renewal of Perspective of Land, Palrom approach in Santos Valley reclamation, Manzar Magazin (18) 60-61 (2011)

3. Florida, Richard Cities and The Creative Class, translated by Ansari Ebrahim and
Ansari Mohammed Ismail, Tehran, Jame-eShenasan Publications (2010).

4. Fruzani, Mohamed Ebrahim, Creative Hub, Strategy of Renewing the Historic Center of the City, Manzar Magazin (19) 80-84 (2011)

5. Farahmand, Erfan Paeez, Post-Industrial, A New Field of Landscape Architecture, Manzar Magazin 3 (16), 22-25 (2010)

6. Samadi, Danial, Place-Based Urban Design: With An Approach to Construct Creative 
Cultural Centers, MS thesis, Unpublished in Tarbiat Modarres University (2012).

7. Dadpour, Sara., The Creation of Attractive Places of Creative Class Using Urban Design :Design Guidelines for Tehran, MS Thesis, Unpublished in Shahid Beheshti University
(2010).

8. Pur Ahmad, Ahmad. Ahmed - Habibi Kiomars - Keshavarz Mahnaz. Evolution of The Concept of A New Approach to Urban Renewal .Iranian Journal of Islamic Studies, . 73 - 93 (2009). 